\title{
Development of an In-row Subsoiler Attachment to Reduce Smearing
}

\author{
R.L. Raper and E.B. Schwab \\ USDA-ARS-National Soil Dynamics Laboratory \\ Conservation Systems Research \\ 411 S. Donahue Drive \\ Auburn, AL 36832 \\ randy.raper@auburn.edu \\ Written for presentation at the \\ 2008 ASABE Annual International Meeting \\ Sponsored by ASABE \\ Rhode Island Convention Center \\ Providence, Rhode Island \\ June 29 - July 2, 2008
}

\begin{abstract}
Hardpans are prevalent throughout the Southeastern United States and frequently cause the depth of crop rooting to be restricted to near the soil surface thus making crops susceptible to short-term droughts. In-row subsoiling has become the tillage tool of choice for alleviation of this compacted soil condition in Coastal Plain soils. However, in many soils with larger amounts of clay, smearing occurs near the bottom of the shank, thus trapping the roots in the subsoiled channel. A novel approach to disturb the bottom of the smeared zone was attempted. Results of multiple experiments involving corn and cotton in multiple soil types indicate that the use of a shank attachment can increase crop yields in fine-textured soils where soil smearing is sometimes noted.
\end{abstract}

Keywords. Subsoiling, strip-tillage, soil compaction, draft, cone index, bulk density, cotton, corn

The authors are solely responsible for the content of this technical presentation. The technical presentation does not necessarily reflect the official position of the American Society of Agricultural and Biological Engineers (ASABE), and its printing and distribution does not constitute an endorsement of views which may be expressed. Technical presentations are not subject to the formal peer review process by ASABE editorial committees; therefore, they are not to be presented as refereed publications. Citation of this work should state that it is from an ASABE meeting paper. EXAMPLE: Author's Last Name, Initials. 2008. Title of Presentation. ASABE Paper No. 08----. St. Joseph, Mich.: ASABE. For information about securing permission to reprint or reproduce a technical presentation, please contact ASABE at rutter@asabe.org or 269-429-0300 (2950 Niles Road, St. Joseph, MI 49085-9659 USA). 


\section{Introduction}

In-row subsoiling is a valuable tillage operation that is frequently used in the Southeastern United States to allow producers to reduce the effects of soil compaction while maintaining adequate amounts of crop residues on the soil surface (Campbell et al., 1974; Box and Langdale, 1984; Raper et al., 1994; Raper et al., 1998; Busscher and Bauer, 2003; Raper, 2005; Raper and Bergtold, 2007). However, the success of this operation is not uniform as some soils that suffer from soil compaction do not respond to in-row subsoiling (Touchton et al., 1986; Raper et al., 2000a; Raper et al., 2000b; Schwab et al., 2002). In the fine-textured alluvial soils of the Tennessee Valley, cover crops were found to be more effective in combating soil compaction than in-row subsoiling. It is hypothesized that soil smearing near the bottom of the trench caused by the in-row subsoiling operation may be responsible for limiting root growth into deeper soil profiles. Evidence of this is sometimes seen by excavating plots where this operation has been conducted. Roots will grow rapidly downward to the bottom of the trench and then will turn horizontally along the path of the subsoiler until they can find a crack or void and can escape.

If this smearing could be avoided, perhaps the use of in-row subsoiling might be a valuable tool for producers who have a severe soil compaction problem. It is the purpose of this research project to determine if an attachment mounted just below and to the rear of a subsoiler shank would sufficiently eliminate soil smearing.

Therefore the objectives of these studies were:

1) Develop and determine the effectiveness of an attachment mounted on a subsoiler shank to improve cotton and corn productivity while not dramatically increasing draft forces,

2) Determine if depth of in-row subsoiling was an important factor in the use of subsoiler attachment.

\section{Methods and Materials}

Three experiments were conducted to evaluate the potential of the spur attachment. The first experiment was begun in the spring of 2004 at the E.V. Smith Research Center in Shorter, Ala. (South-central Alabama) on a Compass loamy sand soil (coarse-loamy, siliceous, subactive, thermic Plintic Paleudults) which is a Coastal Plain soil commonly found in the southeastern U.S. and along the Atlantic Coast of the US. These soils are typically prone to subsoil compaction and usually require annual in-row subsoiling. This experiment focused on a continuous cotton production system. A second experiment was started in 2005 at the same location to evaluate the effect of the spur attachment on a continuous corn production system. It was thought that the fibrous rooted corn systems could potentially have a benefit perhaps unseen by the tap-rooted cotton plants. The third experiment was also begun in 2005 to evaluate another continuous cotton production system at the Tennessee Valley Research and Extension Center in Belle Mina, Ala. (North Alabama) on a Decatur silt loam (Fine, kaolinitic, thermic Rhodic Paleudults) which is a loess soil near the Tennessee River in North Alabama. This soil is not as easily compacted as the Coastal Plains soil, but could be more prone to smearing with its higher clay content. These multiple studies were designed to determine the effect of an in-row subsoiler attachment at two different depths in a conservation tillage system.

The experimental design was a randomized complete block with a 2x2 factorial arrangement of treatments augmented with an additional control treatment of no-tillage for the Tennessee Valley region. A no-tillage treatment was added for this northern region because their soils 
often do not require in-row subsoiling and the use of a cover crop is usually sufficient to cure problems associated with soil compaction. The two factors investigated were: 1) tillage depth (shallow tillage $20 \mathrm{~cm}$, and deep tillage $33 \mathrm{~cm}$ ) and 2) deep tillage attachment (with the in-row subsoiler attachment and without in-row subsoiler attachment. Each treatment was replicated four times (20 plots) at each location. The in-row subsoiler used was a Kelley Manufacturing Company's (Tifton, Ga.) Rip/Strip in-row subsoiler with a straight standard $45^{\circ}$ shank. This inrow subsoiler was used for all treatments that received deep tillage (with and without the attachment).

To determine the shape of the spur, several alternative designs were tested in the soil bins of the USDA-ARS National Soil Dynamics Laboratory in Auburn, Ala. Several designs showed various levels of soil loosening, but for use in the experiment, we decided to use a standard 17tooth sprocket with outside diameter of $9 \mathrm{~cm}$ (Baum Hydraulics Corp., Omaha, Neb.) which was mounted to the rear of the shank for field use (fig. 1). This attachment was commonly referred to as a spur. A United States Patent has been applied for on the device (Raper and Schwab, 2006). A magnetic proximity sensor was also mounted to the bracket holding the spur to ensure adequate rotary velocity as the implement traveled forward.

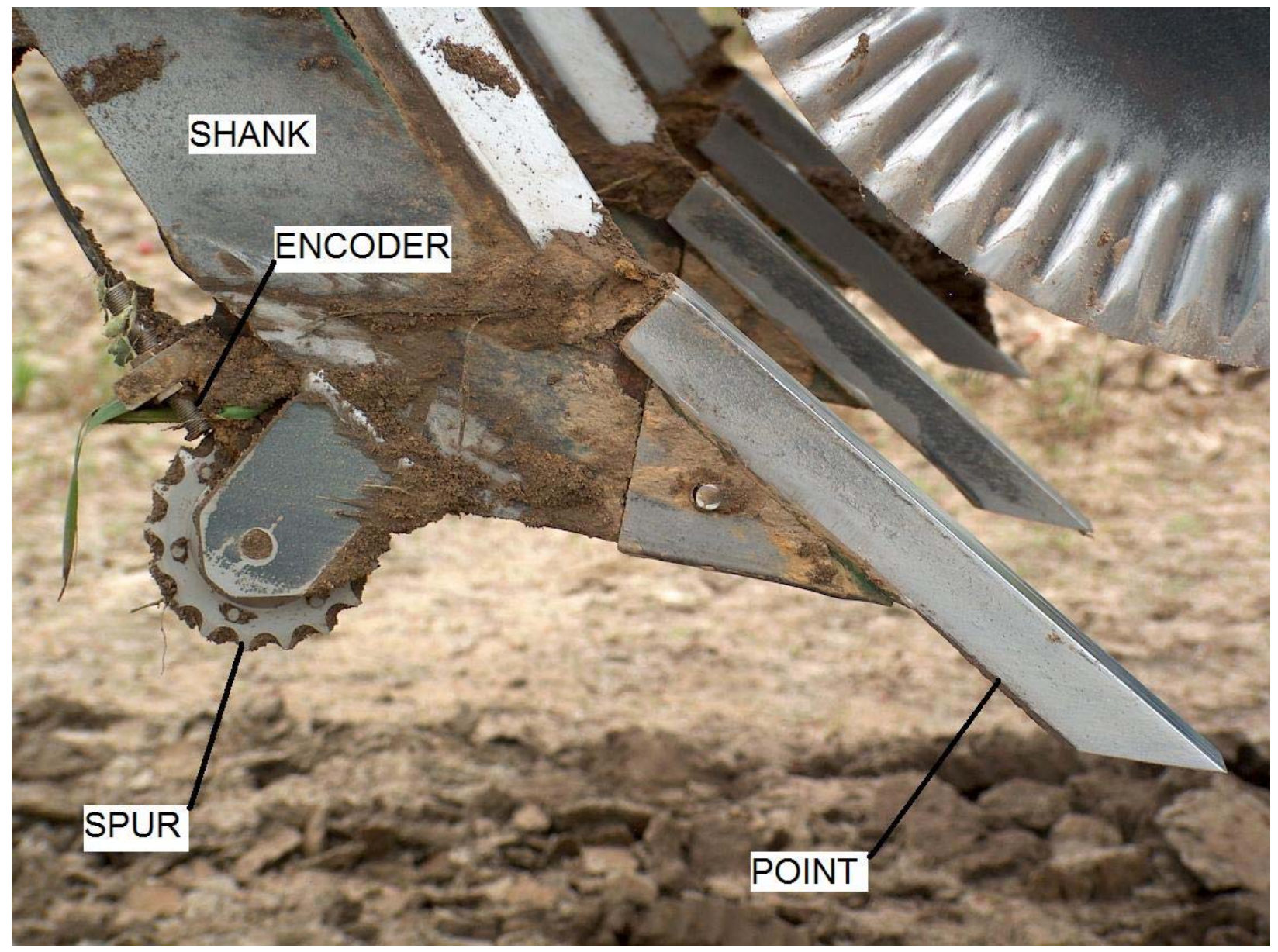

Figure 1. Photo of the in-row subsoiler attachment mounted just below and to the rear of the shank.

As previously stated, experiment 1 consisted of mono-cropping cotton from 2004-2006 in SouthCentral Alabama, experiment 2 consisted of mono-cropping cotton from 2005-2007 in North 
Alabama, and experiment 3 consisted of mono-cropping corn from 2005-2007 in South-Central Alabama. Each of these experiments will be analyzed and discussed separately.

The plots for experiment 1 and 2 were four, $100 \mathrm{~cm}$ rows wide $(4 \mathrm{~m})$ by $15 \mathrm{~m}$ long. For experiment 3 , the plots were four, $0.76 \mathrm{~m}$ rows wide $(3.05 \mathrm{~m})$ by $15 \mathrm{~m}$ long. After the cotton and corn were harvested in the fall, a rye cover crop was planted in experiments 1 and 2 and clover cover crop in experiment 3 until the following spring when the cover crop was terminated by using glyphosate and rolling. Tillage was usually implemented in mid April with the cotton being planted approximately 2 weeks later. Auburn University Extension recommendations were used to apply all fertilizers, herbicides, insecticides, and defoliants. The center two rows were harvested and weighted to obtain seed cotton and corn yield.

A three-dimensional dynamometer was attached between the tractor and the tillage implement at the time of tillage to measure tillage force. This device measured draft, vertical, and side forces required for each tillage treatment. A radar gun was used to obtain tillage speed, which was used along with draft to calculate deep tillage energy. A constant velocity of $4.5 \mathrm{k} / \mathrm{hr}$ was attempted to be maintained throughout the experiments.

Soil strength was determined by use of cone index measurements (ASAE Standards, 2004b; ASAE Standards, 2004a) which were obtained with the Multiple-Probe Soil Measurement System (Raper et al., 1999). These measurements were taken with all five-cone index measurements being equally spaced at a $0.19-\mathrm{m}$ distance across the soil with the middle measurement being directly in the path of the shank.

Data was subjected to ANOVA using the Statistical Analysis System (Littell et al., 1996). Preplanned single degree of freedom contrast and Fisher's protected LSD were used for mean comparisons. A significance level of $\mathrm{P}<0.1$ was established a priori.

\section{Results and Discussion}

\section{Experiment 1-Cotton Production in Coastal Plains of South-Central Alabama}

\section{Soil}

During 2005, an intensive sampling regime was conducted following harvest which consist of obtaining measurements of soil cone index, bulk density, and soil moisture. Cone index showed significant main effects of depth $(p \leq 0.001)$, in-row subsoiling treatments $(p \leq 0.001)$, and measurement position $(p \leq 0.001)$. Also noted were significant interactions between in-row subsoiling treatments and depth $(p \leq 0.001)$, in-row subsoiling treatments and measurement position ( $p \leq 0.001)$, and measurement position and depth $(p \leq 0.001)$. When the in-row position where the shank disturbed the maximum amount of soil was examined, the spur was found to have had little effect on cone index (fig. 2). However, the differences in soil strength from increased tillage depth were clearly demonstrated with shallow in-row subsoiling failing to disrupt the hardpan profile and a root-impeding layer found at depth of $15-35 \mathrm{~cm}$.

Bulk density measurements (fig. 2) taken at the same time closely followed the patterns found in the cone index figures with significant main effects being found for depth $(p \leq 0.001)$ and in-row subsoiling treatment $(p \leq 0.01)$. A significant interaction was also found to occur between depth and in-row subsoiling treatment $(p \leq 0.001)$. Small differences were found as a result of the use of the spur, while differences in tillage depth were clearly noted. Largest values of bulk density were also obtained at the approximate hardpan depths noted by cone index measurements. 
One possible explanation for differences in cone index measurement could be explained by differences in soil moisture. Also, there was potential for the spur to increase infiltration and improve water storage. However, upon examining the data obtained for soil moisture, the only significant effect was found for depth $(p \leq 0.001)$ with greatly increased values of soil moisture found for depths greater than $20 \mathrm{~cm}$ (fig. 2). Only a small increase in soil moisture was found for the spur which occurred only with the use of shallow in-row subsoiling. Also, shallow in-row subsoiling tended to have slightly higher soil moisture at depths lesser than $15 \mathrm{~cm}$ and slightly decreased values of soil moisture at depths greater than $15 \mathrm{~cm}$. This seems reasonable as decreased infiltration would cause rain to be kept shallower thus not penetrating to depths below in-row subsoilling.
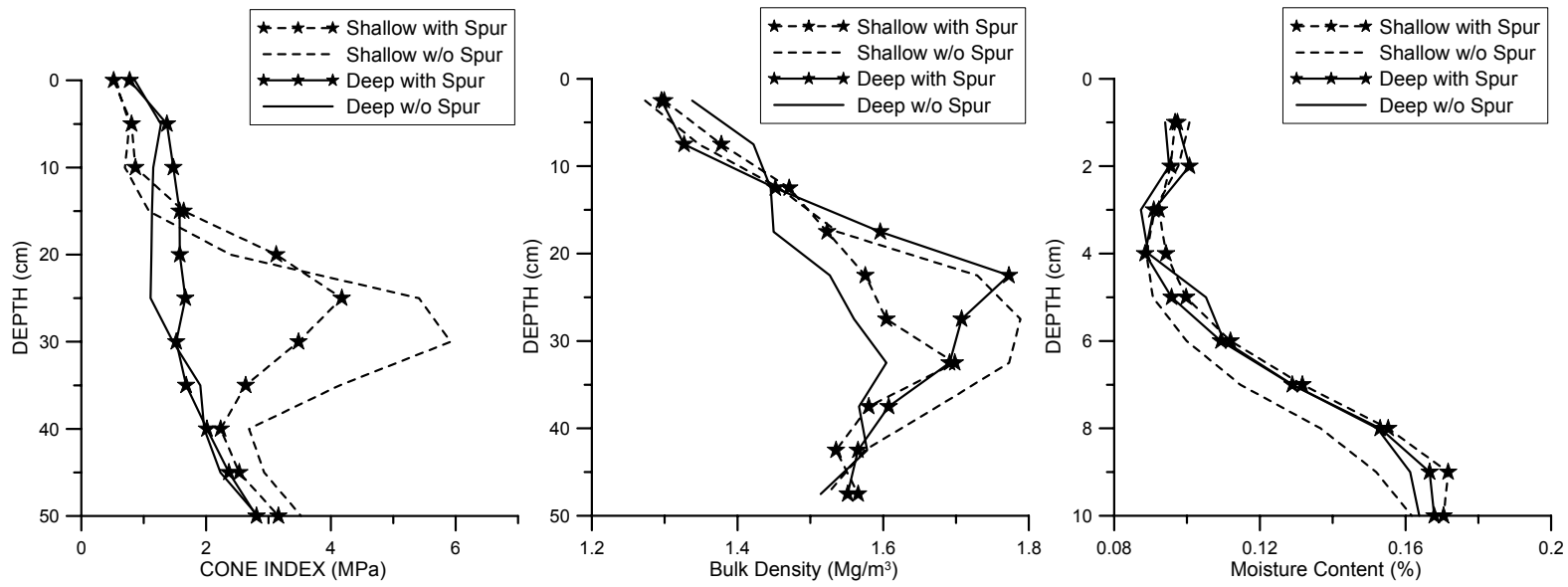

Figure 2. Soil measurements obtained in 2005 in the in-row position for experiment 1: cone index (left), bulk density (center), and soil moisture (right).

Machinery

Draft force was found to be similar for all years of the experiment (fig. 3) with contrasts showing significantly less force being required for shallow in-row subsoiling as compared to deep in-row subsoiling $(2004, p \leq 0.001 ; 2005, p \leq 0.001 ; 2006, p \leq 0.001)$. Shallow in-row subsoiling which was conducted at approximately $60 \%$ of the depth of deep in-row subsoiling was found to require $50 \%$ of the draft force required for deep in-row subsoiling $(15.5 \mathrm{kN}$ vs. $30.9 \mathrm{kN})$. We can use the following equation from ASAE standard D497.4 (2003) to evaluate our experimental values.

$$
D=F_{i}^{*}\left[A+B(S)+C(S)^{2}\right]^{*} W T
$$

where $\mathrm{D}=$ draft, $\mathrm{kN}$

$F_{i}=$ dimensionless soil texture adjustment parameter $\left(F_{1}=1.0, F_{2}=0.7\right.$, and $\left.F_{3}=0.45\right)$

$\mathrm{i}=1$ for fine, 2 for medium, and 3 for coarse textured soils

$$
\begin{aligned}
& \text { A, B, and C are machine-specific parameters }(226,0 \text {, and } 1.8 \text {, respectively) } \\
& S=\text { field speed }(4.5 \mathrm{~km} / \mathrm{hr}) \\
& \mathrm{W}=\text { number of rows }(4) \\
& \mathrm{T}=\text { tillage depth }(23 \text { or } 30 \mathrm{~cm})
\end{aligned}
$$

For our experiment where shallow in-row subsoiling was performed at two depths $(23 \mathrm{~cm}$ and $30 \mathrm{~cm}$ ), we noted that a change in soil texture occurred with shallow layers being coarse and deeper layers being medium texture. Using data from the standard for a narrow point subsoiler, 
we calculated $10.8 \mathrm{kN}$ for shallow in-row subsoiling, and $22.0 \mathrm{kN}$ for deep in-row subsoiling. These values were slightly reduced from the experiment values but are within the $\pm 50 \%$ range advised by the standard.
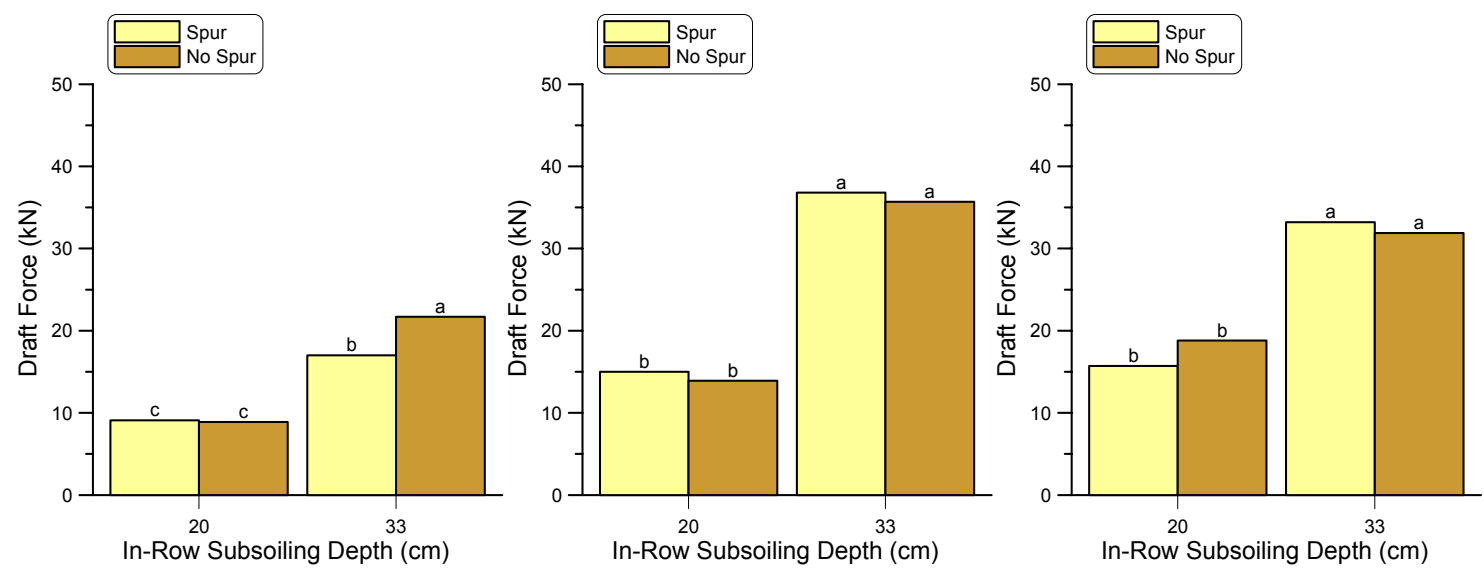

Figure 3. Draft force measurements for experiment 1 obtained in 2004 (left), 2005 (center), and 2006 (right). Letters indicate statistical significance $\left(\mathrm{LSD}_{0.1}\right)$ within years.

Rotational velocity of the spur was measured in 2006 and was found to be significantly affected by tillage depth $(p \leq 0.02)$ with shallow in-row subsoiling having higher angular velocity of 239 rpm as compared to deep in-row subsoiling angular velocity of $219 \mathrm{rpm}$ (fig. 4).

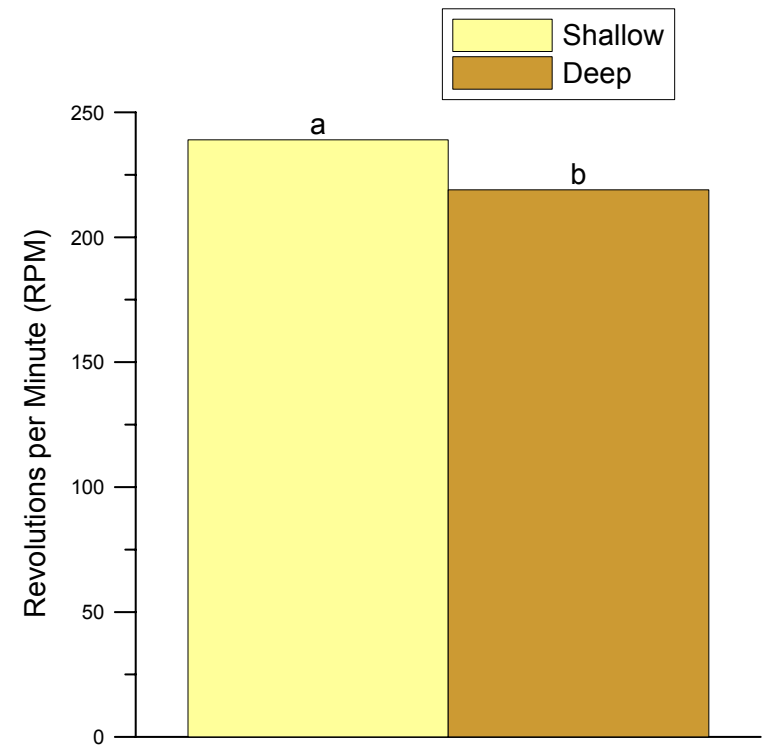

Figure 4. Angular velocity measurements obtained in 2006 for experiment 1.

Crop

Seed cotton yields varied substantially over the three years of the study with significant droughts occurring during the growing season in 2004 and 2006. Seed cotton yield was not affected by the use of the spur on the coarse-textured soils of the Coastal Plains in any of the three years of the study (fig. 5). The only trend that was noted concerning the spur was that slightly increased yields occurred when in-row subsoiling at a shallow depth without the spur. A plausible explanation is that increased infiltration caused by the spur could have decreased the amount of soil moisture present in the profile and made available to cotton plants. 
No differences in seed cotton yield were also found as a result of different depths of in-row subsoiling. This corroborates an earlier publication which indicated that no differences in seed cotton yield were found in Coastal Plains soils as a result of tillage depth (Raper et al., 2007). This also illustrated that substantial savings in energy and fuel consumption could be saved by adjusting in-row subsoilng depth to shallower depths as deeper in-row subsoiling didn't contribute to increased yields and required substantially greater energy.
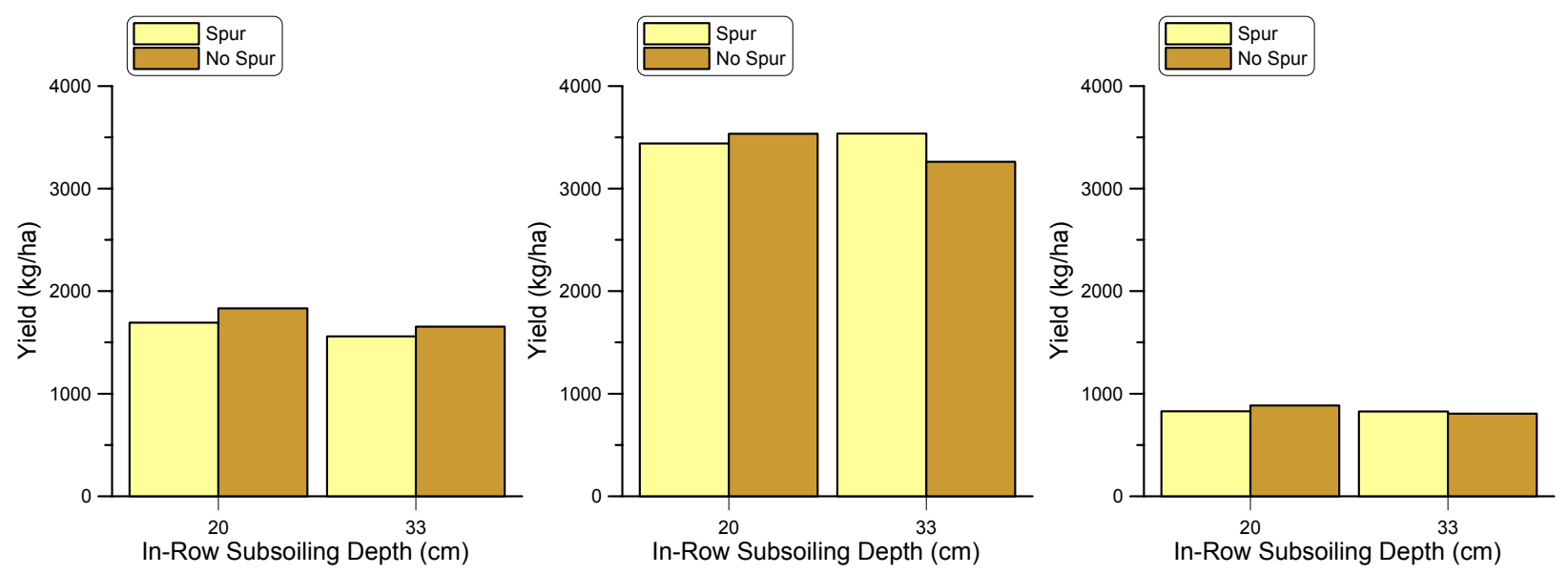

Figure 5. Seed cotton yield for experiment 1 obtained in 2004 (left), 2005 (center), and 2006 (right).

\section{Experiment 2-Cotton Production in Tennessee Valley Region of North Alabama}

\section{Soil}

Cone index values taken in the spring of 2006 after in-row subsoiling treatments had been applied show little effects of the spur (fig. 6). However, differences between shallow and deep in-row subsoiling are visible as well as differences between the tilled plots and the higher soil strength found in the no-till plots. By the end of the growing season of 2006 all of the tilled plots had reconsolidated and had increased in cone index, especially between depths of $5-10 \mathrm{~cm}$ (fig. $6)$. 

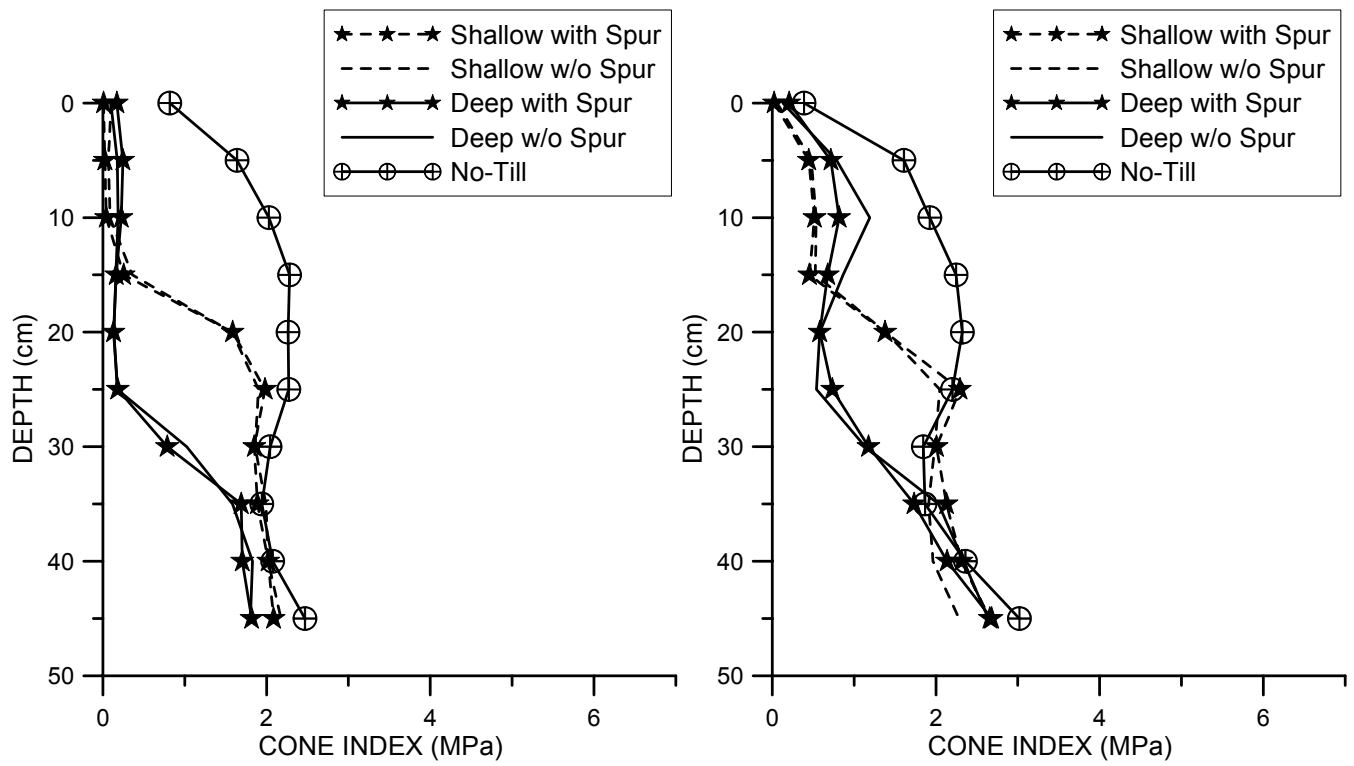

Figure 6. Soil cone index measurements obtained for experiment 2 in 2006 in the spring after planting (left) and after harvest (right).

\section{Machinery}

In 2005, draft force was found to be affected by both depth of in-row subsoiling ( $p \leq 0.001$ ) with shallow in-row subsoiling requiring $19.6 \mathrm{kN}$ and deep in-row subsoiling requiring $40.9 \mathrm{kN}$ and use of the spur $(p \leq 0.06)$ with the attachment requiring an additional $3.8 \mathrm{kN}(32.2 \mathrm{kN}$ with attachment compared to $28.4 \mathrm{kN}$ without the attachment; fig. 7). In 2006, a similar significant effect was noted between tillage depths ( $p \leq 0.001)$ with shallow in-row subsoiling requiring 11.1 $\mathrm{kN}$ and the deep in-row subsoiling requiring $32.4 \mathrm{kN}$. No differences were noted due to the use of the spur. In 2007, statistical differences were again found between in-row subsoiling depths ( $p \leq 0.001$ ) with shallow in-row subsoiling requiring $15.6 \mathrm{kN}$ and deep in-row subsoiling requiring $23.8 \mathrm{kN}$. Again, no differences were found in draft force due to the use of the spur.

Average values of draft measured over the 3-year period were $15.4 \mathrm{kN}$ for shallow in-row subsoiling and $32.4 \mathrm{kN}$ for deep in-row subsoiling. These values were greater than those measured in South-Central Alabama especially for shallow in-row subsoiling and was mostly due to different soil types found in the region. If the shallow soil was assumed to be medium textured and the deeper soil was assumed to be fine textured (which are similar to the assumptions that were made for experiment 1 in South-Central Alabama), $16.9 \mathrm{kN}$ was calculated for shallow in-row subsoiling and $31.5 \mathrm{kN}$ was calculated for deep in-row subsoiling. These values compared very favorably with our measured values. 

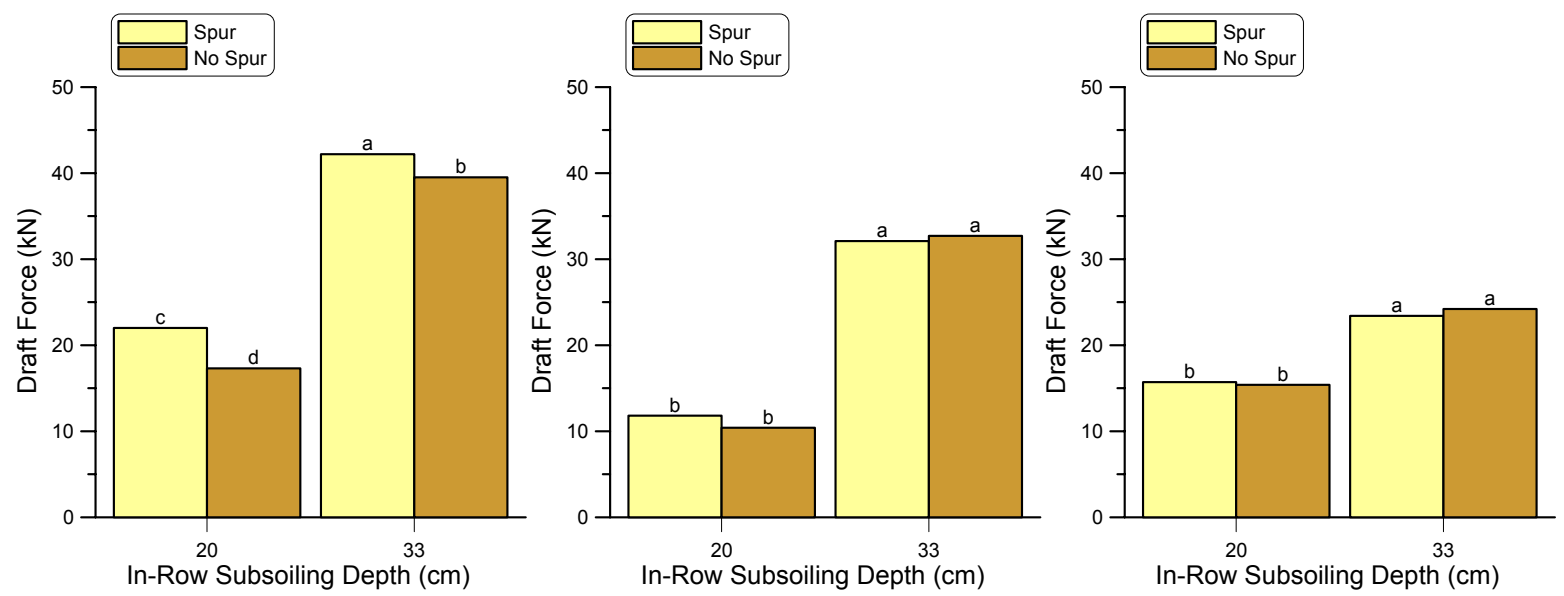

Figure 7. Draft force measurements for experiment 2 obtained in 2005 (left), 2006 (center), and 2007 (right). Letters indicate statistical significance $\left(\mathrm{LSD}_{0.1}\right)$ within years.

\section{Crop}

In 2005, the use of the spur attachment proved to be advantageous to seed cotton yield with significant increases being found due to the use of the device $(2960 \mathrm{lb} / \mathrm{ac}$ for the spur as compared to $2647 \mathrm{lb} / \mathrm{ac}$ with no spur; $\mathrm{p} \leq 0.08$; fig. 8). During this year with adequate soil moisture being found in the soil profile throughout the growing season, the use of the spur improved plant rooting and increased crop yields. Also, when the use of the spur was compared against no-tillage, the spur was found to significantly improve seed cotton yields (2960 lb/ac vs. $2354 \mathrm{lb} / \mathrm{ac} ; \mathrm{p} \leq 0.01$ ). In 2006, the use of the spur again caused improvements in seed cotton yield ( $p \leq 0.1$ ) with the spur increasing yields from $906 \mathrm{lb} / \mathrm{ac}$ to $1042 \mathrm{lb} / \mathrm{ac}$. During this year, no-till was found to be a better production system as compared to in-row subsoiling with no spur $(\mathrm{p} \leq 0.04)$ with no-tillage producing $1120 \mathrm{lb} / \mathrm{ac}$. During the last year of the experiment (2007) when conditions were extremely dry and cotton did not produce well, no differences were found in seed cotton yield due to the use of the spur. However, during this year, no-till caused greater seed cotton yields (1040 lb/ac) as compared to in-row subsoiling with $(707 \mathrm{lb} / \mathrm{ac} ; \mathrm{p} \leq 0.001)$ or without $(731 \mathrm{lb} / \mathrm{ac} ; \mathrm{p} \leq 0.001)$ the use of the spur.
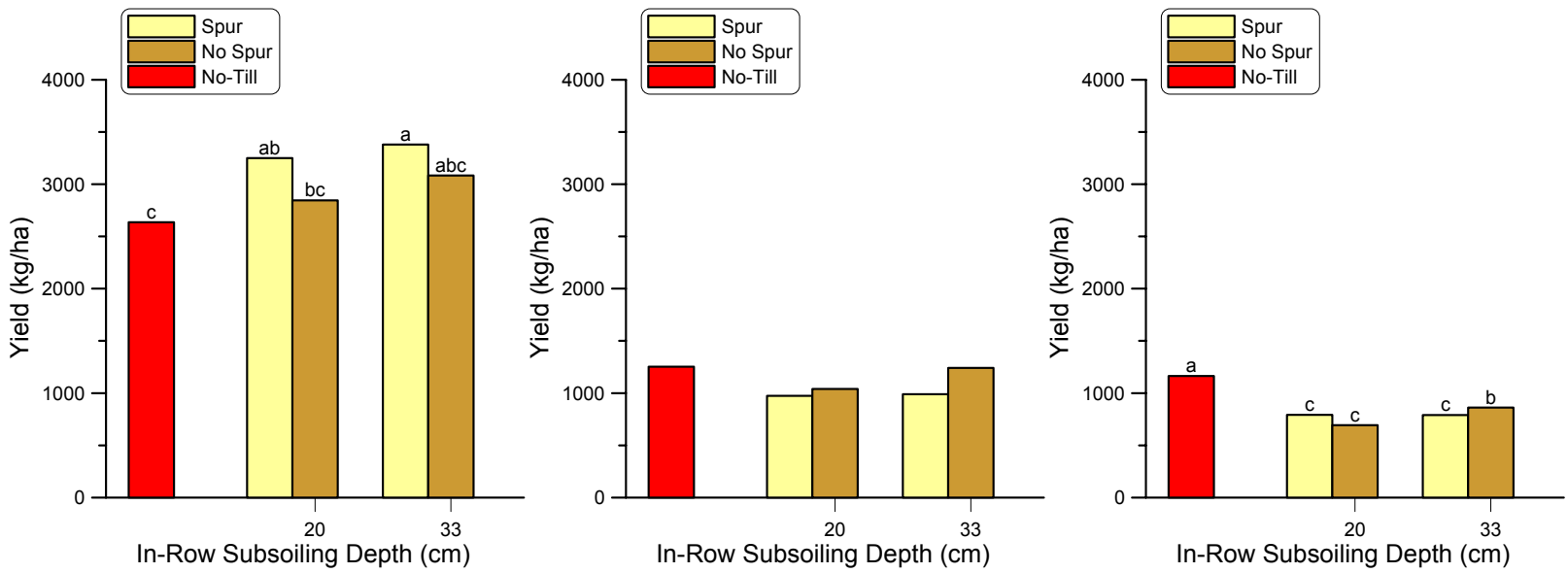

Figure 8. Seed cotton yield for experiment 2 obtained in 2005 (left), 2006 (center), and 2007 (right). Letters indicate statistical significance $\left(\mathrm{LSD}_{0.1}\right)$ within years. 


\section{Experiment 3-Corn Production in Coastal Plains of South-Central Alabama}

\section{Soil}

After harvest of the corn crop in 2005, cone index measurements showed differences in soil strength caused by the depth of in-row subsoiling. These differences were found between depths of 25-40 cm with deep in-row subsoiling having smaller values (fig. 9). Differences in bulk density (fig. 9 center) and soil moisture (fig. 9 right) were not found to be caused by either tillage depth or use of the spur. The only differences noted were due to changes in depth. It is interesting that in nearby plots associated with Experiment 1, more distinct differences in bulk density were noted as a result of tillage depth. One possible explanation is that although the other plots were nearby, rapid changes in soil type were found in this alluvial soil as caused by flooding from the nearby Tallapoosa River.
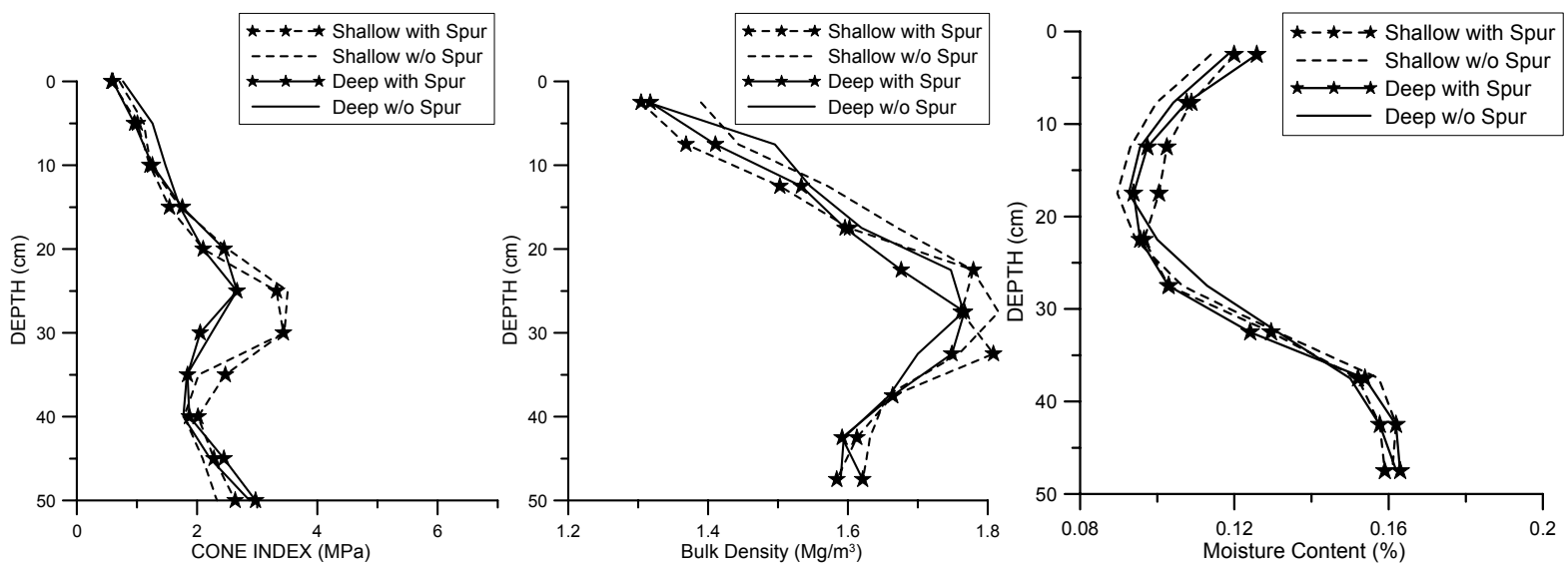

Figure 9. Soil measurements obtained after harvest in 2005 in the in-row position for experiment 3: cone index (left), bulk density (center), and soil moisture (right).

Machinery

In 2005, differences in depth of in-row subsoiling caused differences to be detected in draft energy ( $p \leq 0.001$ ) with shallow tillage requiring $18.6 \mathrm{kN}$ and deep tillage requiring $28.4 \mathrm{kN}$ (fig. 10). In 2006, shallow in-row subsoiling required $12.2 \mathrm{kN}$ which was significantly different than the deeper tillage depth of $28.7 \mathrm{kN}$ ( $p \leq 0.001$ ). In 2007, shallow in-row subsoiling was found to again require significantly reduced draft of $9.3 \mathrm{kN}$ as compared to that required for deep in-row subsoiling (22.4 kN; $p \leq 0.001)$. In none of the 3 years did differences in draft occur due to the use of the spur.

Average measured values of $13.4 \mathrm{kN}$ were found for shallow in-row subsoiling and $26.5 \mathrm{kN}$ for deep in-row subsoiling. Again referring to ASAE Standard D497.4 (2003) for a narrow point subsoiler, $10.8 \mathrm{kN}$ was calculated for shallow in-row subsoiling, and $22.0 \mathrm{kN}$ was calculated for deep in-row subsoiling which were more similar to our experimental values than those found for Experiment 1. 

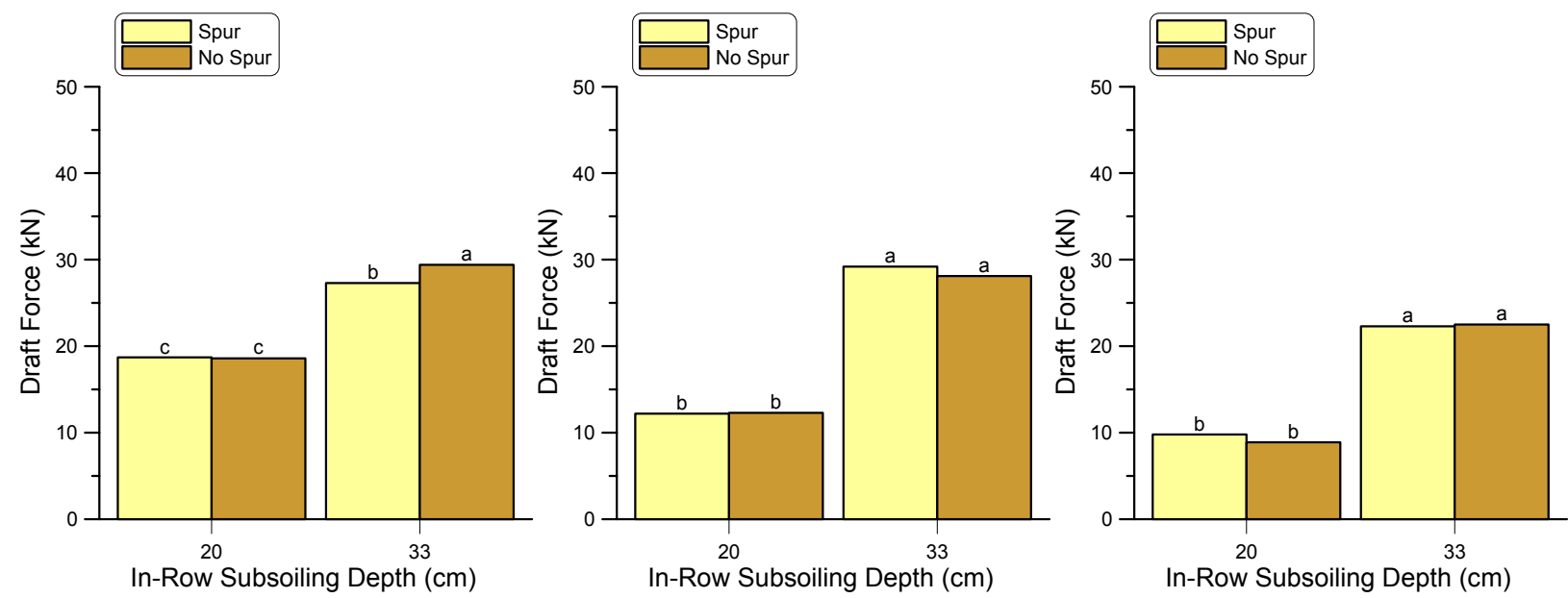

Figure 10. Draft force measurements for experiment 3 obtained in 2005 (left), 2006 (center), and 2007 (right). Letters indicate statistical significance $\left(\mathrm{LSD}_{0.1}\right)$ within years.

Rotational velocity of the spur was measured in 2006 and was found to not be affected by tillage depth with shallow in-row subsoiling having angular velocity of $222 \mathrm{rpm}$ as compared to deep inrow subsoiling angular velocity of 224 rpm (fig. 11).

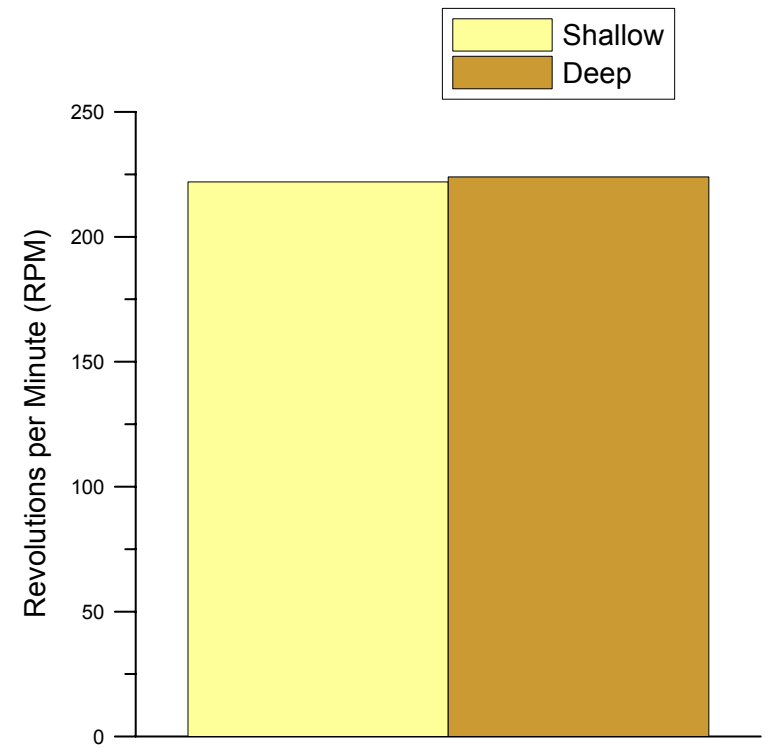

Figure 11. Angular velocity measurements obtained in 2006 for experiment 3.

Crop

Excellent growing conditions prevailed in the South-Central region of Alabama in 2005 and resulted in extremely high dryland corn yields for all treatments (fig. 12). Due to the excellent rainfall patterns during this year, no differences in crop yield were found. However, the same cannot be said for the following 2 years of 2006 and 2007. Devastating droughts occurred during critical periods of corn development and severely limited corn yields both years.

Statistical differences were found in 2006 with shallow in-row subsoiling resulting in higher corn yields $(p \leq 0.002)$ but the yields were so low with shallow in-row subsoiling producing $15.6 \mathrm{bu} / \mathrm{ac}$ and deep in-row subsoiling producing $11.8 \mathrm{bu} / \mathrm{ac}$ that they could be deemed irrelevant. The same trends existed in 2007 except that shallow in-row subsoiling only produced 4.3 bu/ac while 
deep in-row subsoiling produced $3.7 \mathrm{bu} / \mathrm{ac}(\mathrm{p} \leq 0.001)$. However, the yields were again too small to be considered relevant.
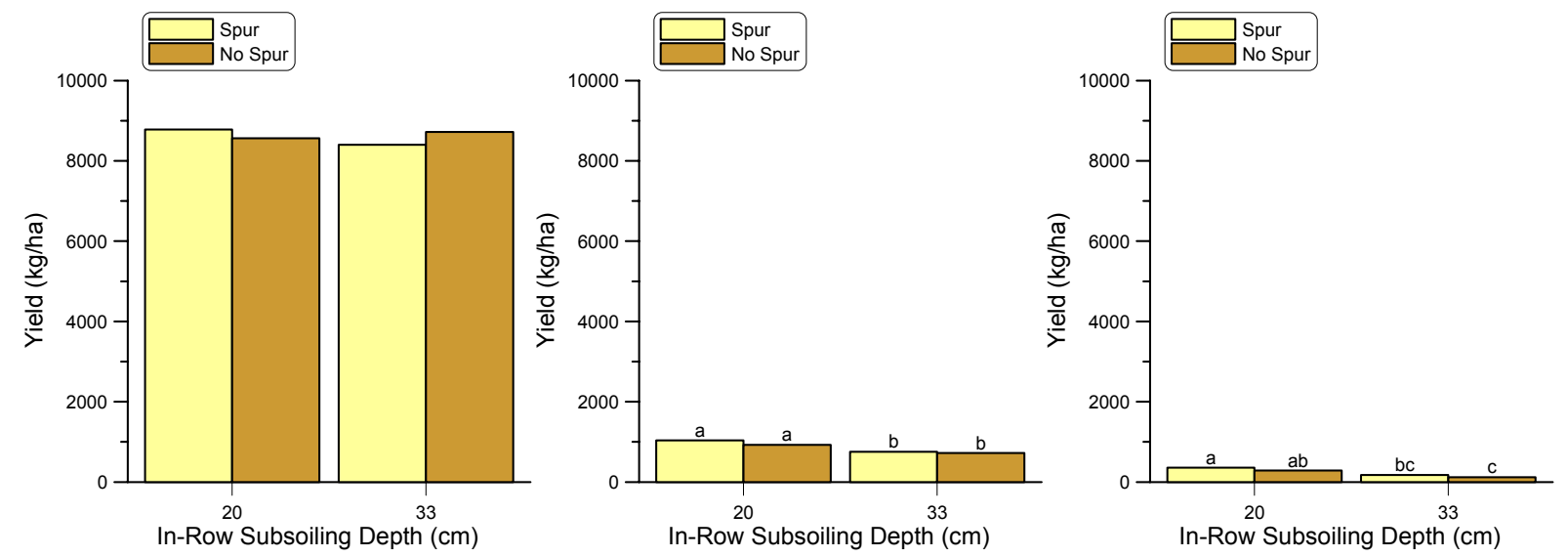

Figure 12. Corn yield for experiment 3 obtained in 2005 (left), 2006 (center), and 2007 (right). Letters indicate statistical significance $\left(\mathrm{LSD}_{0.1}\right)$ within years.

\section{Conclusions}

Results of the three experiments found that the use of the spur was only advisable in finetextured soils which were more prone to smearing. In this soil type, in 2 of 3 years, significant increases in seed cotton yield were found due to the use of the spur. In more coarsely textured soils where soil compaction was more problematic but also where smearing caused by the subsoiling operation was not as readily noted, no advantages of the spur were found.

It was advisable to reduce the depth of in-row subsoiling as deeper depths of tillage did not increase corn or cotton yields in any of the experiments. Also, decreased depth of in-row subsoiling decreased tillage forces which translated into reduced energy usage and fuel consumption required for the in-row subsoiling operation. This conclusion was especially important given the rapidly escalating fuel prices plaguing agriculture.

\section{Disclaimer}

The use of trade names or company names does not imply endorsement by USDA-ARS.

\section{Acknowledgements}

The authors would like to acknowledge the great assistance provided by Mr. Karl Mannschreck, Mr. Dexter LaGrand, Mr. John Walden, and Mr. Morris Welch who have contributed to the success of this project.

\section{References}

ASAE Standards, 49th Edition. 2003. D497.4: Agricultural machinery management data. St. Joseph, Mich.: ASAE.

ASAE Standards, 50th Edition. 2004a. EP542: Procedures for obtaining and reporting data with the soil cone penetrometer. St. Joseph, Mich.: ASAE. 
ASAE Standards, 50th Edition. 2004b. S313.3: Soil cone penetrometer. St. Joseph, Mich.: ASAE.

Box, J., and G.W. Langdale. 1984. The effects of in-row subsoil tillage and soil water on corn yields in the Southeastern coastal plain of the United States. Soil Till. Res. 4(1):67-78.

Busscher, W.J., and P.J. Bauer. 2003. Soil strength, cotton root growth, and lint yield in a southeastern USA coastal loam sand. Soil Till. Res. 74(2):151-159.

Campbell, R.B., D.C. Reicosky, and C.W. Doty. 1974. Physical properties and tillage of Paleudults in the southeastern Coastal Plains. J. Soil Water Cons. 29(5):220-224.

Littell, R.C., G.Milliken, W.W.Stroup, and R.D.Wolfinger. 1996. SAS system for mixed models. Cary, NC.: SAS Institute, Inc.

Raper, R.L. 2005. Subsoiling. In Encyclopedia of Soils in the Environment, pp. 69-75. D. Hillel, D. Rosenzweig, K. Powlson, M. Scow, M. Singer, and D. Sparks, ed. Oxford, U.K.: Elsevier Ltd.

Raper, R.L., and J.S. Bergtold. 2007. In-row subsoiling: a review and suggestions for reducing cost of this conservation tillage operation. Applied Eng. Agric. 23(4):463-471.

Raper, R.L., D.W. Reeves, C.H. Burmester, and E.B. Schwab. 2000a. Tillage depth, tillage timing, and cover crop effects on cotton yield, soil strength, and tillage energy requirements. Applied Eng. Agric. 16(4):379-385.

Raper, R.L., D.W. Reeves, and E. Burt. 1998. Using in-row subsoiling to minimize soil compaction caused by traffic. J. Cotton Sci. 2(3):130-135.

Raper, R.L., D.W. Reeves, E. Burt, and H.A. Torbert. 1994. Conservation tillage and traffic effects on soil condition. Trans. ASAE 37(3):763-768.

Raper, R.L., D.W. Reeves, E.B. Schwab, and C.H. Burmester. 2000b. Reducing soil compaction of Tennessee Valley soils in conservation tillage systems. J. Cotton Sci. 4(2):84-90.

Raper, R.L., D.W. Reeves, J.N. Shaw, E. vanSanten, and P.L. Mask. 2007. Site-specific subsoiling benefits for cotton production in Coastal Plains soils. Soil and Tillage Research 96(1-2):174-181.

Raper, R.L. and E.B. Schwab. 2006. Subsoiler ripper with attachment. United States Patent No. (Application \#11/523,393, filed 9/19/2006).

Raper, R.L., B.H. Washington, and J.D. Jarrell. 1999. A tractor-mounted multiple-probe soil cone penetrometer. Applied Eng. Agric. 15(4):287-290.

Schwab, E.B., D.W. Reeves, C.H. Burmester, and R.L. Raper. 2002. Conservation tillage systems for cotton grown on a silt loam soil in the Tennessee Valley. Soil Sci. Soc. Am. J. 66(2):569-577. 
Touchton, J.T., D.H. Rickerl, C.H. Burmester, and D.W. Reeves. 1986. Starter fertilizer combinations and placement for conventional and no-tillage cotton. J. Fert. Issues 3:9198. 